\title{
PERFORMANCE OF PROMIS-29 (PATIENT REPORTED OUTCOMES MEASUREMENT INFORMATION SYSTEM-29) IN PATIENTS OF RHEUMATIOD ARTHRITIS
}

\author{
Naveed Aslam Lashari, Saira E.A Khan, Shabnam Batool, Asadullah Khan, Zia u din
}

Fatima Memorial Hospital, Lahore Pakistan

\begin{abstract}
Objective: To determine the performance of patient reported outcome measurement information system in patients with rheumatoid arthritis in our setup.

Study Design: Cross sectional study.

Place and Duration of Study: Division of Rheumatology, Fatima memorial hospital, Lahore Pakistan, from May 2019 to Jul 2019.

Methodology: A total of 191 patients of either gender, aged more than 16 years with sero +ve rheumatoid arthritis were included in the study.

Results: Majority of patients $156(81.67 \%)$ were female and male $35(18.32 \%)$ with mean age $38 \pm 12.19$ years. Diagnosed as rheumatoid arthritis and compliant with csDMARDs. Out of all these, majority were in low disease activity (LDA) $72(38 \%)$, remission $62(32 \%)$, moderate $42(22 \%)$ and high disease activity $16(8 \%)$. Mean T-score of all measures showed variations of scores as disease progresses. For all measures, mild change was noted between low disease activity and moderate disease activity whereas high difference was seen in remission and high disease activity. Highest correlations were seen among similar constructs of physical health, mental health, and social health. Fatigue was strongly correlated with social role and social activity.

Conclusion: There was a considerable impact of rheumatoid arthritis on physical, social and mental health calculated with patient reported outcomes measurement information system-29 (PROMIS-29).
\end{abstract}

Keywords: Disease activity score-28, Disease modifying anti rheumatic drugs, Low disease activity, Patient reported outcome measurement information system-29, Rheumatoid arthritis.

This is an Open Access article distributed under the terms of the Creative Commons Attribution License (http://creativecommons.org/licenses/by/4.0), which permits unrestricted use, distribution, and reproduction in any medium, provided the original work is properly cited.

\section{INTRODUCTION}

Rheumatoid arthritis (RA) is most common form of inflammatory arthritis which is characterized by persistent synovial inflammation, bony erosions and articular destruction leading to varying degree of physical disability. It affects less than $1 \%$ of population around the world 1 . The estimated prevalence of RA in developing countries is low as compared to western countries $^{2}$. Reported prevalence of RA in Pakistan ranges from $0.1 \%$ to $0.5 \%{ }^{3}$. Introduction and aggressive use of disease modifying and biological agents in RA have markedly decrease the disability related to disease ${ }^{4}$. Different measures of patient outcome such as different disease activity measures can facilitate clinical decision making to achieve desired outcome like remission and low

Correspondence: Dr Naveed Aslam Lashari, Rheumatologist and Classified Medical Specialist, PAF Hospital, Islamabad Pakistan Received: 25 Jul 2019; revised received: 23 Sep 2019; accepted: 24 Sep 2019 disease activity LDA 5 . Around the world, there has been debate on the role of data in supporting to improve quality of life in patients with various chronic diseases including rheumatoid arthritis ${ }^{6}$. In this regard, the most recent method is patient reported outcome measurement information system (PROMIS) developed by National Institutes of Health which helps to measure physical, mental and social health effectively in single questionnaire in various diseases, medical and surgical procedures. PROMIS instruments are publicly made available in short forms (SF) and computerized adaptive tests (CAT) and have been tested in large no of the population 7,8 . PROMIS-29 is gaining popularity in RA over its conventional disease activity measures like SDAI, CDAI and DAS-28 with its ability to detect small changes at low level of symptoms and disability in patients at minimal disease activity which helps to optimize disease modifying anti-rheu- 
matic drugs (DMARDs) ${ }^{9}$. Treat to target strategy in RA patient is mandatory to achieve remission or low disease activity (LDA) and has been considered superior outcome to standard care in RA as endorsed by ACR, EULAR and other professional organizations ${ }^{10}$. It aims to capture and quantify the outcomes that are important to health of patient so it has been adapted by some advanced countries as an indicator of health care qualities for different chronic diseases including RA, different medical and surgical procedures, even new countries are entering in this list ${ }^{11}$. The rationale of this study is to determine the role of PROMIS29 questionnaire in improvement of quality of health care in rheumatoid arthritis. In Pakistan, this patient reported outcome system has been used very less in Rheumatology, so it would be an optimal, cost effective and easy option to report the outcome of disease and improve quality of life in such patients.

To determine the performance of patient reported outcome measurement information system (PROMIS-29) in Rheumatoid arthritis in our clinical setting.

\section{METHODOLOGY}

This was a cross sectional study carried out in the Division of Rheumatology, Fatima Memorial Hospital, Lahore from May 2019 to July 2019. A total of 191 patients using 5\% level of significance and $80 \%$ power of the test, $1 \%$ margin of error with $0.5 \%$ prevalence of Rheuma-toid arthritis were included in this study. All patients (either gender) of age 16 years and on word, diagnosed as seropositive rheumatoid arthritis according to ACR/EULAR criteria with good compliance with prescribed medicines were included in the study by non probability consecutive sampling. Patients with overlap or mixed connective tissue disorders and noncompliant to prescribed medicines were excluded. Patient were interviewed in Rheumatology OPD while informed written consent was recorded (IRB\# FMH04-2019-IRB-611-M). Demographics like case no, gender, age \& address were noted. Detailed history regarding disease and compliance to medicine were asked and DAS-28 score was calculated. Questions regarding physical health (physical functions, pain intensity, pain interference and fatigue), mental health (depression, anger and anxiety) and social health (ability to participate in social roles and activities) were asked and noted on PROMIS-29 questionnaire/ proforma. All collected information was entered in online PROMIS scoring system (CAT). All scales were scored as recommended and converted to $\mathrm{T}$ scores, with a population mean of 50 and SD 10 as standardized. For all PROMIS scales, higher scores reflected "more" of the construct being measured. For example social roles, social activity and physical functions with higher scores showed better functioning and satisfaction and were considered as better whereas higher scores in depression, anger, anxiety, pain interference/ intensity and fatigue were considered as "worst".

Data were entered and analyzed by using SPSS-23. All the quantitative variables like age and score for constructs of PROMIS were presented in the form of Mean \pm SD. Categorical variables were presented in the form of frequency and percentage. Constructs of PROMIS were graphically represented by histograms with normal curve. Pearson's correlation was used to assess the relationship between physical, mental and social health. Data was stratified according to the DAS-28 disease activity levels and Kruskal Wallis test was applied post stratification. A $p$-value less than 0.05 was considered significant.

\section{RESULT}

A total of 191 patients with the mean age of $38 \pm 12.19$ years were enrolled in the study in

Table-I: Participant characteristics ( $n=191)$.

\begin{tabular}{l|c}
\hline Characteristic & Value \\
\hline Age & $38 \pm 12$ years \\
\hline Female gender & $156(82 \%)$ \\
\hline Male gender & $35(18 \%)$ \\
\hline DAS-28 & \\
\hline Remission & $62(32 \%)$ \\
LDA & $72(38 \%)$ \\
Moderated & $42(22 \%)$ \\
High & $16(8 \%)$ \\
\hline
\end{tabular}


which $156(81.67 \%)$ were female and 35 (18.33\%) were male. They reflected a diverse spectrum of RA character in disease presentation and drug response. All patient were diagnosed case of rheumatoid arthritis as per criteria for RA on initial same questions in general population) ${ }^{12}$ of each group are shown in (table-I). Correlations of individual PROMIS scales were compared among construct of Physical health (physical functions, pain intensity, pain interference and fatigue),

Table-II: Correlations.

\begin{tabular}{|c|c|c|c|c|c|c|c|c|c|c|}
\hline 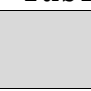 & & Anxiety & Anger & $\begin{array}{l}\text { Depres- } \\
\text { sion }\end{array}$ & Fatigue & $\begin{array}{c}\text { Pain } \\
\text { interference }\end{array}$ & $\begin{array}{c}\text { Pain } \\
\text { behavior }\end{array}$ & $\begin{array}{l}\text { Physical } \\
\text { function }\end{array}$ & $\begin{array}{c}\text { Social } \\
\text { activity }\end{array}$ & $\begin{array}{c}\text { Social } \\
\text { roles }\end{array}$ \\
\hline$\frac{\substack{0 \\
\frac{\pi}{2}}}{2}$ & $\begin{array}{c}\text { Pearson } \\
\text { correlation } \\
\text { P-value }\end{array}$ & 1 & $\begin{array}{l}.899^{* *} \\
.000\end{array}$ & $\begin{array}{l}.879^{* *} \\
.000\end{array}$ & $\begin{array}{l}.794^{* *} \\
.000\end{array}$ & $\begin{array}{l}.793^{* *} \\
.000\end{array}$ & $\begin{array}{l}.743^{* *} \\
.000\end{array}$ & $\begin{array}{l}-.129 \\
.074\end{array}$ & $\begin{array}{c}-.168^{*} \\
.020\end{array}$ & $\begin{array}{l}-.168^{*} \\
.020\end{array}$ \\
\hline $\begin{array}{l}\dot{8} \\
\stackrel{0}{<}\end{array}$ & $\begin{array}{c}\text { Pearson } \\
\text { correlation } \\
\text { P-value }\end{array}$ & $\begin{array}{l}.899 * * \\
.000\end{array}$ & 1 & $\begin{array}{l}.861^{* *} \\
.000\end{array}$ & $\begin{array}{l}.805^{* *} \\
.000\end{array}$ & $\begin{array}{l}.784^{* *} \\
.000\end{array}$ & $\begin{array}{l}.831^{* *} \\
.000\end{array}$ & $\begin{array}{r}-.115 \\
.114\end{array}$ & $\begin{array}{r}-.158^{*} \\
.029\end{array}$ & $\begin{array}{l}-.164^{*} \\
.024\end{array}$ \\
\hline$\frac{\mathscr{D}}{\frac{1}{2}} \cdot \frac{5}{0}$ & $\begin{array}{c}\text { Pearson } \\
\text { correlation } \\
\text { P-value }\end{array}$ & $\begin{array}{l}.879 * * \\
.000\end{array}$ & $\begin{array}{l}.861^{* *} \\
.000\end{array}$ & 1 & $\begin{array}{l}.925^{* *} \\
.000\end{array}$ & $\begin{array}{l}.920 * * \\
.000\end{array}$ & $\begin{array}{l}.834^{* *} \\
.000\end{array}$ & $\begin{array}{c}-.195^{* *} \\
.007\end{array}$ & $\begin{array}{c}-.221^{* *} \\
.002\end{array}$ & $\begin{array}{c}-.246^{* *} \\
.001\end{array}$ \\
\hline 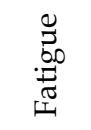 & $\begin{array}{c}\text { Pearson } \\
\text { correlation } \\
\text { P-value }\end{array}$ & $\begin{array}{l}.794^{* *} \\
.000\end{array}$ & $\begin{array}{l}.805^{* *} \\
.000\end{array}$ & $\begin{array}{l}.925^{* *} \\
.000\end{array}$ & 1 & $\begin{array}{l}.931^{* *} \\
.000\end{array}$ & $\begin{array}{l}.848^{* *} \\
.000\end{array}$ & $\begin{array}{c}-.325^{\star *} \\
.000\end{array}$ & $\begin{array}{c}-.357^{* *} \\
.000\end{array}$ & $\begin{array}{c}-.393^{* *} \\
.000\end{array}$ \\
\hline . & $\begin{array}{c}\text { Pearson } \\
\text { correlation } \\
\text { P-value }\end{array}$ & $\begin{array}{l}.793^{* *} \\
.000\end{array}$ & $\begin{array}{l}.784^{* *} \\
.000\end{array}$ & $\begin{array}{l}.920 * * \\
.000\end{array}$ & $\begin{array}{l}.931^{* *} \\
.000\end{array}$ & 1 & $\begin{array}{l}.828^{* *} \\
.000\end{array}$ & $\begin{array}{c}-.228^{* *} \\
.002\end{array}$ & $\begin{array}{c}-.267^{* *} \\
.000\end{array}$ & $\begin{array}{c}-.299 * * \\
.000\end{array}$ \\
\hline . & $\begin{array}{c}\text { Pearson } \\
\text { correlation } \\
\text { P-value }\end{array}$ & $\begin{array}{l}.743^{* *} \\
.000\end{array}$ & $\begin{array}{l}.831^{* *} \\
.000\end{array}$ & $\begin{array}{l}.834^{* *} \\
.000\end{array}$ & $\begin{array}{l}.848^{* *} \\
.000\end{array}$ & $\begin{array}{l}.828^{* *} \\
.000\end{array}$ & $\begin{array}{c}1 \\
.000\end{array}$ & $\begin{array}{c}-.293^{* *} \\
.000\end{array}$ & $\begin{array}{c}-.296^{* *} \\
.000\end{array}$ & $\begin{array}{c}-.327^{* *} \\
.000\end{array}$ \\
\hline 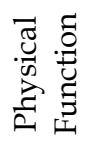 & $\begin{array}{c}\text { Pearson } \\
\text { correlation } \\
\text { P-value }\end{array}$ & $\begin{array}{l}-.129 \\
.074\end{array}$ & $\begin{array}{r}-.115 \\
.114\end{array}$ & $\begin{array}{c}-.195^{\star *} \\
.007\end{array}$ & $\begin{array}{c}-.325^{* *} \\
.000\end{array}$ & $\begin{array}{c}-.228^{* *} \\
.002\end{array}$ & $\begin{array}{c}-.293^{* *} \\
.000\end{array}$ & 1 & $\begin{array}{l}.923^{* *} \\
.000\end{array}$ & $\begin{array}{l}.823^{* *} \\
.000\end{array}$ \\
\hline 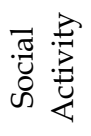 & $\begin{array}{c}\text { Pearson } \\
\text { correlation } \\
\text { P-value }\end{array}$ & $\begin{array}{c}-.168^{*} \\
.020\end{array}$ & $\begin{array}{l}-.158^{*} \\
.029\end{array}$ & $\begin{array}{c}-.221^{* *} \\
.002\end{array}$ & $\begin{array}{c}-.357^{* *} \\
.000\end{array}$ & $\begin{array}{c}-.267^{* *} \\
.000\end{array}$ & $\begin{array}{c}-.296^{* *} \\
.000\end{array}$ & $\begin{array}{l}.923^{* *} \\
.000\end{array}$ & 1 & $\begin{array}{l}.877^{* *} \\
.000\end{array}$ \\
\hline 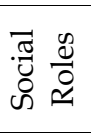 & $\begin{array}{c}\text { Pearson } \\
\text { correlation } \\
\text { P-value }\end{array}$ & $\begin{array}{l}-.168^{*} \\
.000\end{array}$ & $\begin{array}{c}-.164^{*} \\
.024 \\
\end{array}$ & $\begin{array}{c}-.246^{* *} \\
.001 \\
\end{array}$ & $\begin{array}{c}-.393^{* *} \\
.000\end{array}$ & $\begin{array}{c}-.299 * * \\
.000\end{array}$ & $\begin{array}{c}-.327^{* *} \\
.000\end{array}$ & $\begin{array}{l}.803^{* *} \\
.000 \\
\end{array}$ & $\begin{array}{l}.877^{* *} \\
.000\end{array}$ & 1 \\
\hline
\end{tabular}

${ }^{*}$ Correlation is significant at the 0.05 level (2-tailed), ${ }^{* *}$ Correlation is significant at the 0.01 level (2-tailed).

visits ${ }^{12}$. All patients were on conventional DMARDs with majority $72(38 \%)$ patients in low disease activity (LDA) as DAS-28 score, 62 (32\%) in remission, $42(22 \%)$ in moderate disease and $16(8 \%)$ in high disease activity. Mean T-scores (Tscore is standardized score that is based on an average score of 50 , based on responses to the mental health (depression, anger and anxiety) and social health (ability to participate in social roles and activities) (table-II). Highest correlations were seen among similar construct of physical health, mental health, and social health. Fatigue was strongly correlated with social role and social activity. In general, PROMIS scores worse- 
ned significantly as disease activity progressed from remission to high disease activity (table-III). Anxiety, anger and depression worsened by almost 6 to 10 points whereas fatigue, pain interference, pain behavior, physical function, social activity and social roles by 12 to 15 points. Similar worsening trends were observed for most of the measures in different disease activities but scores were not significantly different in LDA and moderate disease activities. In all PROMIS measures, lowest increase in impairment were noted in scales of mental health from remission to LDA (avg: 3.6 points), whereas highest impairment in physical health and social health measure (avg: 6.5 points). Similar pattern was observed in moderate to high disease activity but slight change were seen in different measures of PROMIS scale from LDA to moderate disease activity.

\section{DISCUSSION}

This study is first to report in our setup where different instruments of PROMIS-29 Tscores were evaluated and compared in patients of RA. All instruments were completed in <9 minutes by $80 \%$ of patients and showed considerable impact of RA on social, mental and physical health of patient. Like other disease activity score used in RA, there was significant worsening of T-scores of all instruments noted with worsening of disease. In this study, average incline among $\mathrm{T}$ scores and worsening of mental health remained lower than physical health and pain which points towards the physical disability caused by RA. Lowest increase in impairment was noted among the scales of mental health from remission to LDA and highest impairment was observed in physical health and social health, which showed the different effects of disease activity on PROMIS. Correlation were similar among scales of mental health, physical health and pain. These findings contribute new evidence and support as outcomes in patient of RA in our region. Similar results were found in different international studies/trials, which support superiority of PROMIS in RA patients ${ }^{13,19}$. These scales were initially developed for research purposes to obtain the estimate of patients' symptoms in diff- erent diseases and procedures ${ }^{13}$. In patient with rheumatoid arthritis, different parameters were assessed using common T-score metric, which showed wide distribution and reported significant impairment as disease progressed (fig-1). However fatigue, emotional distress and social participation are not currently evaluated as per previous guidelines in RA ${ }^{14}$. Now it is recommended that patient relevant symptoms through qualitative inquiry, cognitively debriefed potential items and rigorously psychometrically analysis should be included in PROs to monitor disease activity ${ }^{13,15-17}$. Moreover, parameter like depression which is not being evaluated in conventional scales shows less responsive in PROMIS scale $^{18}$. Whereas, all aspects of physical function were comprehensively assessed according to ICF core set for RA except assisting others, driving and moving around using equipment. Excellent results were obtained with this scale for all parameters including isolated fatigue ${ }^{19,20}$. This scale will also provide research on less well studied impact of these factors in all other diseases ${ }^{21}$. In recent years this scale is well used and found efficient in other rheumatological disorders like SLE, OA, fibromyalgia22. Emerging treatment modalities in RA have also been evaluated during their trial phases with PROMIS scale. HAQ-DI scores were converted to this scale in phase 3 clinical trial of baricitinib and considerable results were obtained ${ }^{24}$.

Scale is also translated in multiple languages for patients and showed same expected results ${ }^{24,25}$. The current target for patient with RA is to achieve disease remission or LDA, it requires accurate, precise and reliable measurement of symptoms and functional impact of disease on patient ${ }^{16}$. With development of biologics and early diagnostic measures, many people reach at remission or LDA. In our sample, $70 \%$ were at these targets, however none of patients were on biologics. Composite RA disease activity measures (disease activity score [DAS-228], simplified disease activity index [SDAI], clinical disease activity index [CDIA]) rely on answers to a global question about disease activity / health status and 
ESR or CRP. Other multidimensional measures like SF-36 and HAQ are proprietary and burdensome to complete in clinical setting. From all these available instruments, we selected PROMIS
-29 CAT to focus on measureable outcomes which are either practical to obtain from patient (impact) or can directly be asked (symptoms). PROMIS CATs offers precise, practical and imm-

Table-III: (PROMIS and legancy scores by DAS-28 disease activity levels).

\begin{tabular}{l|c|c|c|c|c} 
& $\begin{array}{c}\text { Remission } \mathbf{( n = 6 2 )} \\
\text { Mean } \pm \text { SD }\end{array}$ & $\begin{array}{c}\text { Low }(\mathbf{n}=\mathbf{7 2}) \\
\text { Mean } \pm \text { SD }\end{array}$ & $\begin{array}{c}\text { Moderate } \mathbf{( n = 4 2 )} \\
\text { Mean } \pm \text { SD }\end{array}$ & $\begin{array}{c}\text { High }(\mathbf{n}=\mathbf{1 5}) \\
\text { Mean } \pm \text { SD }\end{array}$ & $\boldsymbol{p}$-value \\
\hline Anxiety & $40.35 \pm 8.4$ & $44.00 \pm 7.91$ & $43.45 \pm 7.6$ & $46.26 \pm 2.9$ & 0.0001 \\
\hline Anger & $38.14 \pm 7.30$ & $42.55 \pm 7.6$ & $41.97 \pm 7.3$ & $45.00 \pm 4.4$ & 0.0001 \\
\hline Depression & $43.85 \pm 7.81$ & $46.22 \pm 8.05$ & $47.22 \pm 5.1$ & $52.00 \pm 4.1$ & 0.0001 \\
\hline Fatigue & $45.08 \pm 6.52$ & $51.11 \pm 8.3$ & $52.14 \pm 4.4$ & $59.66 \pm 4.09$ & 0.0001 \\
\hline Pain interference & $48.58 \pm 7.7$ & $52.81 \pm 8.1$ & $53.02 \pm 4.8$ & $62.60 \pm 4.1$ & 0.0001 \\
\hline Pain behavior & $38.19 \pm 7.27$ & $46.11 \pm 7.79$ & $47.64 \pm 4.71$ & $51.26 \pm 3.9$ & 0.0001 \\
\hline Physical function & $52.01 \pm 4.02$ & $45.11 \pm 4.96$ & $40.07 \pm 3.8$ & $39.73 \pm 7.1$ & 0.0001 \\
\hline Social Activity & $56.22 \pm 3.9$ & $49.27 \pm 4.6$ & $43.33 \pm 4.7$ & $42.46 \pm 7.1$ & 0.0001 \\
\hline Social Roles & $56.45 \pm 3.8$ & $49.61 \pm 4.2$ & $48.59 \pm 4.56$ & $43.33 \pm 6.4$ & 0.0001
\end{tabular}

Scales with higher scores like social roles, social activity and physical functions with higher scores showed better functioning and satisfaction. Whereas higher scores in depression, anxiety, anger, pain interference/intensity and fatigue were considered as "worst".
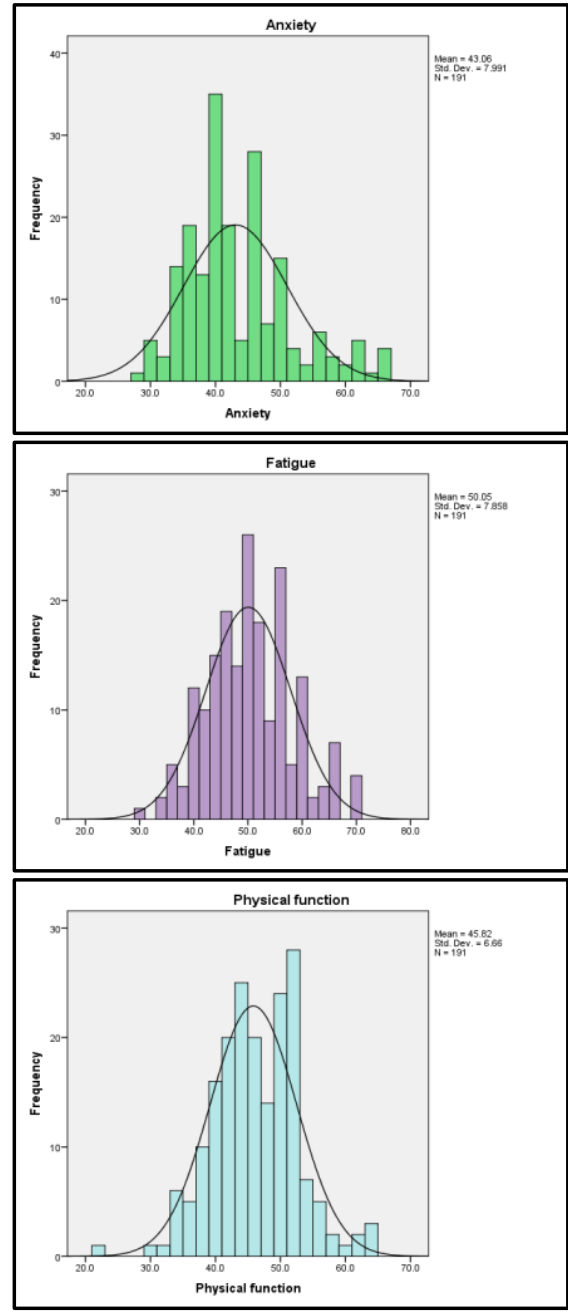
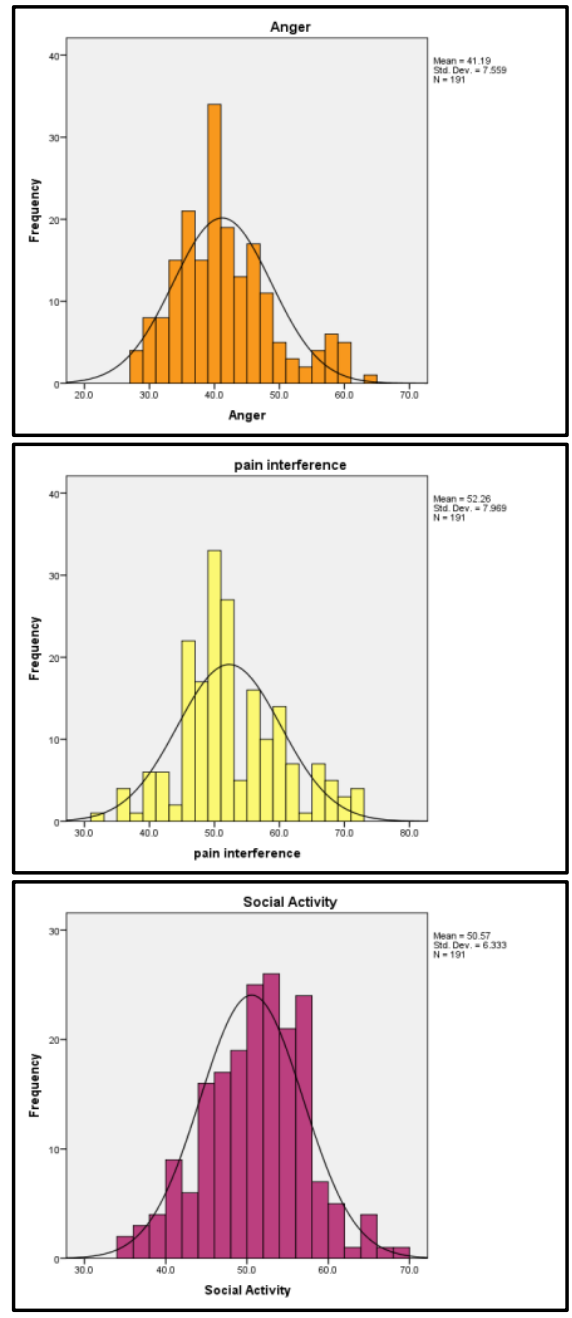
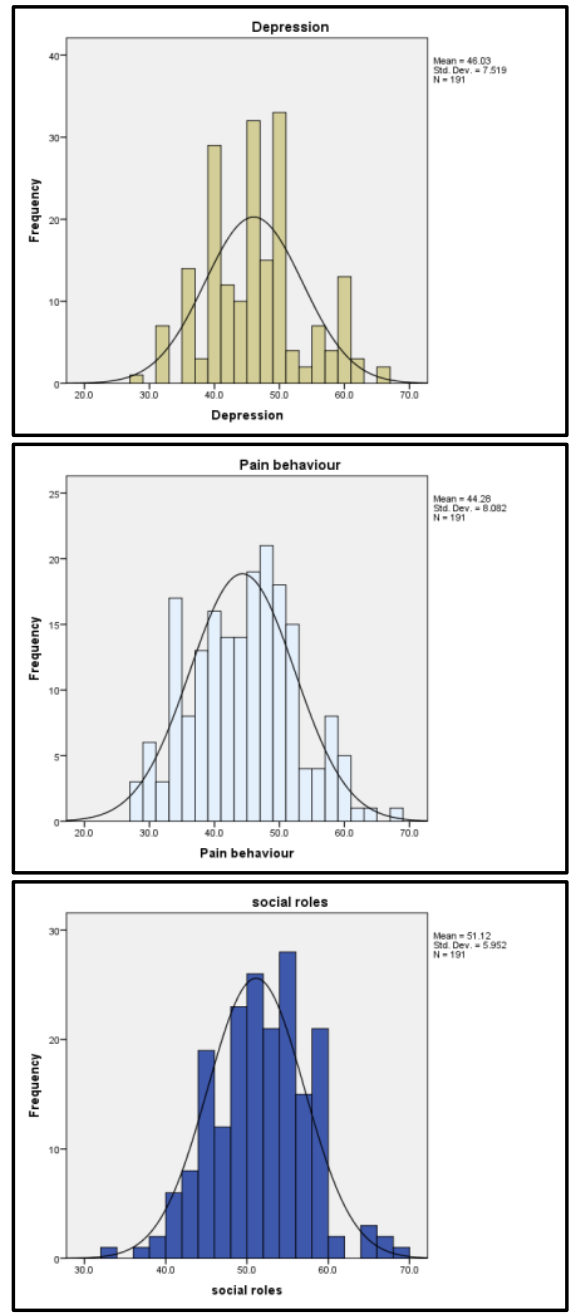

Figure: T score distribution for patient reported outcomes measurement information system (PROMIS). 
ediate disease response which covers important aspects of RA like physical, mental and pain measures. The ability of PROMIS to address and detect minute changes in symptoms in targeted disease activity offers new perception in RA patients to minimize physical disability and achieve treat to target approach. In addition, the PROMIS measures can be used freely and can be accessed on-line in multiple languages. There are limitation to this study. Participant were mostly uneducated who require assistance to fill online form. Majority of patients were in either remission or LDA with mean age $38 \pm 12$ years and average disease duration 10 years. None of the patient was on biologics and all patients were on csDMARDs. Patients with later age groups and short duration of disease activity may respond differently on PROMIS scale. Future analysis should extend examination of PROMIS-29 on patients obtaining different bDMARDs and individuals on low compliance. Former will show deep remission response and later may be especially important to know which aspect of PROMIS scales gives high score in such patients. PROMIS scales should be made available in local languages of this region like urdu, sindhi and pashto for understanding of disease activity with PROMIS score in such patients.

\section{CONCLUSION}

Results showed considerable impact of RA on physical, social and mental health of patients. This work provided initial data supporting applicability and practicality of PROMIS-29 for monitoring disease activity and research in inflammatory condition like RA.

\section{CONFLICT OF INTEREST}

This study has no conflict of interest to be declared by any author.

\section{REFERENCES}

1. Lawrence RC, Helmick CG, Arnett FC, Deyo RA, Felson DT, Giannini EH, et al. Estimates of the prevalence of arthritis and selected musculoskeletal disorders in the United States. Arthritis Rheum 1998; 41(5): 778-99.

2. Alam SM, Kidwai AA, Jarfi SR, et al. Epidemiology of Rheumatiod arthritis in a tertiary care unit, karachi, Pakistan. J Pak Med Assoc 2011; 61(2): 123-26.
3. Farooqi A, Gibson T. Prevalence of the major rheumatic disorders in the adult population of North Pakistan. Br J Rheumatol 1998; 37(5): 491-95.

4. Krishnan E, Lingala B, Bruce B, Fries JF. Disability in Rheumatiod arthritis in the era of biological treatments. Ann Rheum Dis 2012; 71(2): 213-18.

5. Smolen JS, Aletaha D, Bijlsma JW, Breedveld FC, Boumpas D, Burmester G, et al. Treating rheumatoid arthritis to target: recommendations of an international task force. Ann Rheum Dis 2010; 69(4): 631-37.

6. Martin GP, McKee L, Dixon-Woods M. Beyond metrics? Utilizing 'soft intelligence' for healthcare quality and safety. Soc Sci Med 2015; 142(1): 19-26.

7. Valderas JM, Alonso J. Patient reported outcome measures: a model-based classification system for research and clinical practice. Qual Life Res 2008; 17(9): 1125-35.

8. Cella D, Riley W, Stone A, Rothrock N, Reeve B, Yount S, et al. The Patient-Reported Outcomes Measurement Information System (PROMIS) developed and tested its first wave of adult self-reported health outcome item banks: 2005-2008. J Clin Epidemiol 2010; 63(11): 1179-94.

9. Bartlett SJ, Orbai AM, Duncan T, DeLeon E, Ruffling V, Cleggsmith $\mathrm{K}$, et al. Reliability and validity of selected PROMIS measures in people with rheumatoid arthritis. PLoS One 2015; 10(9): e0138543.

10. Nikiphorou E, Norton S, Young A, Carpenter L, Dixey J, Walsh $\mathrm{D}$, et al. Treating rheumatoid arthritis to target is low disease activity good enough?. EMJ Rheumatol 2018; 5(1): 45-45.

11. Van der Wees PJ, Nijhuis-Van der Sanden MWG, Ayanian JZ, Black N, Wstert GP, Schnerder EC, et al. Integrating the use of patient-reported outcomes for both clinical practice and performance measurement: views of experts from 3 countries. Milbank Quart 2014; 92(4): 754-75.

12. Kay J, Katherine S, Upchurch. ACR/EULAR 2010 rheumatoid arthritis classification criteria. Rheumatol 2012; 51(6): vi5-vi9.

13. Orbai AM, Bingham CO. Patient reported outcomes in Rheumatoid arthritis clinical trials. Curr Rheumatol Rep 2015; 17(4): 501.

14. Carole A, Tucker, Cieza A, Anne W, Riley, Stucki G, et al. Concept analysis of the patient reported outcomes measurement information system (PROMIS) and the international classification of functioning, disability and health (ICF). Qual Life Res 2014; 23(6): 1677-86.

15. Aletaha D, Landewe R, Karonitsch T, Bathon, Boers M, Bombardier S, et al. Reporting disease activity in clinical trials of patients with rheumatoid arthritis: EULAR/ACR collaborative recommendations. Ann Rheum Dis 2008; 67(10): 1360-64.

16. Singh JA, Furst DE, Bharat A, Curtis JR, Kavanaugh AF, Kremer JM, et al. Update of the 2008 American College of Rheumatology recommendations for the use of disease-modifying antirheumatic drugs and biologic agents in the treatment of rheumatoid arthritis. Arthritis Care Res 2012; 64(5): 625-39.

17. Food and Drug Administration. Guidance for industry on patient-reported outcome measures: Use in medical product development to support labeling claims. Federal Register 2009; 74(235): 65132-33.

18. Smolen JS, Landewe R, Breedveld FC, Buch M, Burmester G, Dougados $M$. et al. EULAR recommendations for the management of rheumatoid arthritis with synthetic and biological disease-modifying antirheumatic drugs: 2013 update. Ann Rheum Dis 2014; 73(3): 492-509.

19. Wohlfahrt A, Bingham CO III, Marder W, Phillips K, Bolster MB, Moreland LW, et al. Responsiveness of patient reported outcomes measurement information system (PROMIS) measures in 
RA patients starting or switching a DMARD. Arthritis Care Res (Hoboken) 2019; 71((4): 521-29.

20. Voshaar O, Peter M, Glas CA, Vonkeman HE, Taal E, Krishnan $\mathrm{E}$, et al. Validity and measurement precision of the PROMIS physical function item bank and a content validity driven 20 item short form in rheumatoid arthritis compared with traditional measures. Rheumatology (Oxford) 2015; 54(12): 2221-29.

21. Bartlett SJ, Gutierrez AK, Butanis, Bykek VP, Curtis JR, Ginsberg $\mathrm{S}$, et al. Combining online and in-person methods to evaluate the content validity of PROMIS fatigue short forms in rheumatoid arthritis. Qual Life Res 2018; 27(9): 2443-51.

22. Karzan IL, Lapin B. PROMIS GH (Patient reported outcomes measurement information system global health) scale in stroke.
Stoke 2018; 49(1): 147-54.

23. Katz P, Pedro S, Michaud K. Performance of the patient reported outcomes measurement information system 29 -item profile in rheumatoid arthritis, osteoarthritis, fibromyalgia and systemic lupus erythematosus. Arthritis Care Res 2017; 69(9): 1312-21.

24. Bingham CO, Gaich C, DeLozier AM, Quebe A, Sun L, Otawa. FRI0013 converting patient reported physical function outcomes scores to promis metric scores in phase 3 trial of bariciti-nib in rheumatoid arthritis. Ann Rheumatic Dis 2018; 77(1): 553-54.

25. Mahmoud GA, Rady HM, Mostafa AM. Cross cultural adaptation and validation of an Arabic version of selected PROMIS measures for use in rheumatoid arthritis patients. Egyptian Rheumatol 2018; 9(1): 3-10. 